\title{
O ENSINO SUPERIOR PERANTE AS DEMANDAS DA EDUCAÇÃO INCLUSIVA: O QUE PENSAM OS GESTORES DA UNIVERSIDADE FEDERAL DE OURO PRETO
}

\author{
Higher Education and the demands of inclusive education: the vision of the managers of \\ the Federal University of Ouro Preto
}
Educación Superior frente a las demandas de la educación inclusiva: lo que piensan los gestores de la Universidad Federal de Ouro Preto

Marco Antônio Melo Franco ${ }^{1}$

Marcilene Magalhães da Silva ${ }^{2}$

Carla Mercês da Rocha Jatobá Ferreira ${ }^{3}$

\begin{abstract}
Resumo
A crescente demanda no campo da educação inclusiva, que vem se tornando pauta na Educação Superior, tem, de alguma maneira, contribuído para o repensar dessa etapa de formação. Faz-se necessária a tomada de posição das instituições no sentido de diminuir as barreiras que dificultam o pleno exercício do direito dos cidadãos que, agora, nela adentram. Para tanto, investigamos como os gestores da Universidade Federal de Ouro Preto (Ufop) concebem três conceitos que entendemos fundamentais para a implementação de políticas inclusivas, sendo eles: inclusão, interculturalidade e inovação pedagógica. Por meio da aplicação de questionários, realizamos a coleta de dados nos diferentes níveis de gestão da universidade. Do total de 120 questionários aplicados 38 foram respondidos. Foi possível observar que os gestores possuíam um maior conhecimento sobre o tema da inclusão, o que não se estendeu aos outros dois conceitos. Podemos considerar que as respostas apontam para a necessidade de construir um campo de estudos e debates acerca dos conceitos investigados, no intuito de promover a formação no âmbito da instituição e, assim, garantir que a educação inclusiva seja central nas ações da Ufop.
\end{abstract}

PALAVRAS-CHAVE: Educação Superior. Inclusão. Interculturalidade. Inovação pedagógica.

\footnotetext{
Abstract

The growing demand in the field of inclusive education that has become a subject in Higher Education has contributed to the rethinking of this stage of education. It is necessary for higher education institutions to step up the barriers that hinder the full exercise of the right of citizens who are now studying it. In this research, we investigate how the managers of the

1 Professor Adjunto do Departamento de Educação e do Programa de Pós-Graduação em Educação da Universidade Federal de Ouro Preto. Membro do Observatório Internacional de Inclusão, Interculturalidade e Inovação Pedagógica. E-mail: <mamf.franco@gmail.com>.

2 Técnica em Assuntos Educacionais da Universidade Federal de Ouro Preto. Membro do Observatório Internacional de Inclusão, Interculturalidade e Inovação Pedagógica. E-mail: <marcilenemag@ gamil.com>.

${ }^{3}$ Professora Adjunta do Centro de Educação Aberta e a Distância da Universidade Federal de Ouro Preto. Membro do Observatório Internacional de Inclusão, Interculturalidade e Inovação Pedagógica. E-mail: <carlajatobaferreira@gmail.com>.
} 
Federal University of Ouro Preto (Ufop) understand three fundamental concepts for the implementation of inclusive policies: inclusion, interculturality and pedagogical innovation. Data collection was performed through the application of 120 questionnaires with 38 respondents. From the answers it was possible to observe that the managers had a greater knowledge on the theme of inclusion, unlike the other two concepts. We can consider that the answers reveal the need to build a field of studies and debates about the concepts investigated. This can contribute to promote training in universities and to ensure that inclusive education is central to Ufop's actions.

KEYWORDS: College education. Inclusion. Interculturality. Pedagogical innovation.

\section{Resumen}

La creciente demanda en el campo de la educación inclusiva, que viene convirtiéndose en pauta en la Educación Superior, ha contribuido, de alguna manera, para repensar esta formación. Se hace necesaria la toma de posición de las instituciones de enseñanza para disminuir las barreras que dificultan el pleno ejercicio del derecho de los ciudadanos excluidos que ahora entran en ella. Considerando estas perspectivas, investigamos cómo los gestores de la Universidad Federal de Ouro Preto (Ufop) conciben tres conceptos que son fundamentales para la implementación de políticas inclusivas: inclusión, interculturalidad e innovación pedagógica. Por medio de la aplicación de cuestionarios realizamos la recogida de datos en los diferentes niveles jerárquicos de la gestión de la universidad. Se aplicaron 120 cuestionarios y 38 personas respondieron. A partir de las respuestas se observó que los gestores poseían un mayor conocimiento sobre el tema de la inclusión, lo que no se extendió a los otros dos conceptos. Podemos considerar que las respuestas apuntan a la necesidad de construir un campo de estudios y debates acerca de los conceptos investigados, con el fin de promover la formación en el ámbito de la institución universitaria y, así, garantizar que la educación inclusiva sea central en las acciones de la Ufop.

PALABRAS CLAVE: Educación Superior. Inclusión. Interculturalidad. Innovación pedagógica.

\section{INTRODUÇÃO}

As discussões sobre a educação que atenda às diferenças ganharam força no cenário mundial com a Declaração Mundial sobre Educação para Todos (1990) e com a Declaração de Salamanca (1994). Esses documentos consideram que o modo como atuam os sistemas educacionais contribui para a exclusão de muitos estudantes, passando a influenciar fortemente na formulação das políticas públicas, particularmente no campo da educação inclusiva.

Posteriormente a essas Declarações, vários dispositivos legais indicaram requisitos de acessibilidade $^{4}$ e de inclusão, em todos os níveis educacionais, de pessoas historicamente

\footnotetext{
${ }^{4}$ Prover as instituições de Educação Superior de condições de acessibilidade é materializar os princípios da inclusão educacional que implicam assegurar não só o acesso, mas também condições plenas de participação e de aprendizagem a todos os estudantes.
} 
excluídas. No caso do Ensino Superior, instruíram processos de autorização e de reconhecimento de cursos e de credenciamento de instituições.

Nessa perspectiva, a análise de uma postura intercultural, inovadora e inclusiva no Ensino Superior insere-se em, pelo menos, duas problemáticas mais amplas: a luta histórica pela democratização ${ }^{5}$ do acesso ao Ensino Superior e as condições ainda adversas enfrentadas por diferentes sujeitos ao longo do percurso de escolarização.

Com relação à primeira problemática, apesar das grandes transformações pelas quais tem passado o Ensino Superior brasileiro, é notório que a expansão não o democratizou efetivamente, havendo marcas históricas da exclusão (BRASIL, 2011). Sobre a segunda problemática, não se questiona se a escola, nos diferentes níveis de ensino, deve, ou não, receber todos os estudantes, reconhecer seus distintos contextos socioculturais e valorizar suas diferenças, um direito constitucional ${ }^{6}$ (SANTOS, 2003). Temos constatado, entretanto, que a exclusão ainda ocorre no Ensino Superior, de vários modos, muitas vezes velados, entre sujeitos diversos. A Universidade tem como desafio constituir-se como espaço para superar os estigmas negativos concernentes às diferenças dos seus estudantes.

Como afirma Wanderley (2001), a consolidação do processo de democratização no País também faz pensar que o trabalho de combate às desigualdades educacionais tem de fornecer níveis de proteção que garantam o exercício da cidadania, o respeito e a valorização das diferenças. É, pois, no contexto de democratização do acesso ao Ensino Superior que se abrigam o debate e a defesa com relação a uma atitude intercultural, inovadora e inclusiva que assegure aos estudantes o ingresso, a permanência e a formação acadêmica de qualidade.

Ouvir os sujeitos implicados nas ações educacionais (estudantes, professores, gestores, técnicos) pode ser fundamental para desvelar concepções, valores, conflitos e práticas excludentes. Principalmente, pode contribuir com a institucionalização de uma política que se configure em uma proposta de mediação intercultural, inovadora pedagogicamente e inclusiva. Trata-se de possibilitar o diálogo para potencializar a ação desencadeada pelos conflitos, muitas vezes silenciados, colaborando para novas formas de exclusão.

Portanto, o texto propõe trazer para o debate questões acerca dos conceitos inclusão, interculturalidade e inovação pedagógica, particularmente como são compreendidas pelos

\footnotetext{
${ }^{5}$ Entendemos como garantia de acesso, permanência e conclusão com êxito.

${ }^{6}$ A política de inclusão educacional encontra respaldo na Constituição da República Federativa do Brasil de 1988, artigo 3. ${ }^{\circ}$, inciso IV, que versa sobre a aplicação do princípio inclusivo: "Promover o bem de todos sem preconceito de origem, raça, sexo, cor, idade e quaisquer outras formas de discriminação".
} 
gestores da Universidade Federal de Ouro Preto (Ufop). ${ }^{7}$ Para tanto, está dividido em três partes. Na primeira, é apresentado um panorama dos conceitos em estudo. Na segunda, os procedimentos metodológicos da investigação. Na terceira, apresentação e análise dos dados coletados a partir da pesquisa.

\section{INTERCULTURALIDADE, INOVAÇÃO PEDAGÓGICA E INCLUSÃO: PERSPECTIVAS DOS TEMAS NA EDUCAÇÃO}

Ao definirmos as temáticas interculturalidade, inovação pedagógica e inclusão como condutoras desta investigação, fez-se necessário evidenciar como esses referenciais têm sido considerados por estudiosos do assunto. Como conceitos educacionais, eles precisam ser entendidos como acontecimento social e mundial, para, posteriormente, serem internalizados pela sociedade e construídos coletivamente, principalmente nas universidades.

\section{Interculturalidade}

Interessa-nos, aqui, discutir em que consiste a educação intercultural ${ }^{8}$ e quais os desafios para sua implementação no interior de nossas universidades. Existe hoje uma rica literatura que envolve o conceito, com diferentes terminologias e perspectivas que se expressam nas teorias e propostas interculturais, tendo como eixo conceitual comum a possibilidade do respeito e a valorização das diferenças humanas. Abordaremos considerações sobre o tema com base em autores como Fleuri (2002, 2003) e Candau (2002, 2009, 2011), por melhor dialogarem com nossos estudos e perspectivas.

Fleury (2003, p. 31) compreende interculturalidade como um conceito baseado no respeito à diferença, que se concretiza no reconhecimento da paridade de direitos. Trata-se de um campo complexo envolvendo diferentes sujeitos sociais, perspectivas epistemológicas e políticas diversas, distintas práticas e contextos sociais. Para o autor, "enfatizar o caráter

\footnotetext{
7 A Ufop está localizada na Região Sudeste, em Minas Gerais, e foi criada em 21 de agosto de 1969, pelo Decreto-lei n. ${ }^{\circ}$ 778, a partir da fusão de duas escolas isoladas, a Escola de Farmácia, fundada em 1839, e a Escola de Minas e Metalurgia, de 1876. No momento da pesquisa, contava com três campi, 11 unidades acadêmicas, 43 cursos de graduação, 68 cursos de pós-graduação, cerca de 13 mil e 400 alunos regularmente matriculados nos cursos de graduação, 847 professores e 808 técnicos administrativos em Educação.

8 A perspectiva de uma educação intercultural ganhou importância no Brasil a partir da divulgação dos Parâmetros Curriculares Nacionais (1997), com o desenvolvimento de políticas de inclusão educacional das minorias étnicas, raciais, geracionais, de gênero e de pessoas com deficiência.
} 
relacional e contextual (inter) dos processos sociais permite reconhecer a complexidade, a polissemia, a fluidez e a relacionalidade dos fenômenos humanos e culturais".

Candau (2009, p.170) também indica essa complexidade, ao afirmar que a educação intercultural não pode ser reduzida a determinadas situações e atividades realizadas em momentos específicos, nem focalizar sua atenção exclusivamente em determinados grupos sociais, por exemplo, o grupo das pessoas com deficiência, o grupo geracional, o grupo étnico, entre outros. "Trata-se de um enfoque global que deve afetar todos os atores e todas as dimensões do processo educativo, assim como os diferentes âmbitos em que ele se desenvolve." Nesse sentido, a educação intercultural afeta as escolas e as universidades sob vários aspectos: na relação entre os diferentes sujeitos que dela participam, no fortalecimento de uma cultura intercultural, na seleção dos currículos, na elaboração das políticas e na efetivação das práticas pedagógicas.

A interculturalidade, tal como definida pelos autores, traz implicações importantes para o campo da educação e configura-se numa proposta de educação para a defesa aos direitos de todos, à igualdade de dignidade e de oportunidade entre os diferentes sujeitos sociais. Fleuri (2002) defende que a interculturalidade pode contribuir para superar barreiras atitudinais advindas da intolerância, de preconceitos, de medos e de estigmas negativos ante o outro, construindo uma disponibilidade para a leitura positiva da diferença humana.

No entanto, o trabalho com as diferenças nas universidades ainda é algo a se alcançar e tem nos desafiado a caminhar nessa direção, haja vista as situações de tensão e exclusão apontadas em estudos diversificados que tratam da inclusão no Ensino Superior, mostrando a complexidade do processo e os desafios postos à escola no contexto atual.

O desenvolvimento de uma educação intercultural na perspectiva apresentada por Fleuri e Candau é uma questão complexa, marcada por tensões e desafios. Sabemos que o tratamento dado ao tema nas universidades ainda se restringe à introdução de componentes das culturas de diferentes grupos, nos currículos dos cursos de graduação. Para Romero (2010, p. 29), "de nada vale afirmar a perspectiva intercultural se se mantiverem a discriminação, a segregação". Por outro lado, grupos socioculturais distintos conquistam acesso aos mais elevados níveis de ensino, intensificando as situações de conflito e criando um ambiente favorável para se assegurar o debate sobre a educação intercultural.

\section{Inovação Pedagógica}

Revista Educação e Fronteiras On-Line, Dourados/MS, v.8, n.22, p.115-130, jan./abr. 2018119 
Para tratarmos do conceito de inovação pedagógica fazem-se necessárias, inicialmente, algumas considerações. Para Veiga (2003), tal conceito pode ser pensado em duas perspectivas: a primeira como uma ação regulatória e a segunda como uma ação emancipatória. A autora descreve como ação regulatória um modelo de inovação que se pauta na racionalidade técnica.

De acordo com Veiga (2003), a inovação regulatória tem como base epistemológica a ciência conservadora e normativa. Ela se caracteriza pela certeza ordenada, por padronizações, por transformar os resultados em normas e prescrições a serem aplicadas. "Este modelo deixa de fora os sujeitos como protagonistas do institucional, desprezando as relações e as diferenças entre eles, não reconhecendo as relações de força entre o institucional e o contexto social mais amplo" (VEIGA, 2003, p. 270).

Por outro lado, ao abordar o conceito de inovação emancipatória, Veiga (2003) considera-o como uma produção humana. A autora parte do pressuposto de que, nessa abordagem, as bases epistemológicas estão calcadas no caráter emancipatório e argumentativo da ciência. Nessa perspectiva, os diferentes saberes dialogam em função de um objeto comum e evidenciam-se situados em um contexto sócio-histórico específico. A inovação emancipatória encontra-se imbuída de intencionalidade que implica processos construtivos que se opõem a processos institucionalizados e padronizados.

As duas abordagens apresentadas levam-nos a refletir sobre o que poderíamos chamar de prática pedagógica. Adotando o caráter emancipatório como orientador da nossa reflexão, podemos entender que, ao se tratar de práticas pedagógicas, é fundamental considerar o sujeito como ator desse processo, cumprindo um papel fundamental na sua configuração. Nesse sentido, Franco (2015) auxilia-nos definindo as práticas pedagógicas como práxis, as quais "[...] ocorrem em meio a processos que estruturam a vida e a existência". Para a autora, as práticas pedagógicas constituem-se na mediação com o outro, sendo esse outro aquele que pode oferecer a essas práticas a sua existência. Para Franco (2015, p. 604):

As práticas pedagógicas são aquelas práticas que se organizam para concretizar determinadas expectativas educacionais. São práticas carregadas de intencionalidade e isso ocorre porque o próprio sentido de práxis configura-se através do estabelecimento de uma intencionalidade, que dirige e dá sentido à ação, solicitando uma intervenção planejada e científica sobre o objeto, com vistas à transformação da realidade social. 
A autora deixa claro o caráter intencional da prática, suas tensões e contradições, uma vez que envolve diferentes sujeitos em sua constituição. Tal perspectiva exigirá ações de acompanhamento, de vigília e de readequação constantes que estão para além de modelos padronizados e estanques. Nesse caso, a abordagem emancipatória contrapõe-se terminantemente à abordagem regulatória.

Conforme Cunha (2016), a concepção de inovação pedagógica deve ser tomada em uma perspectiva de ruptura paradigmática. Não se trata apenas de mudanças metodológicas na forma do fazer pedagógico e no uso de instrumentos tecnológicos. Para ela, a concepção de inovação passa pela adição de uma nova maneira de pensar e compreender o conhecimento, o que significa uma mudança nas bases epistemológicas do fazer pedagógico. De acordo com Cunha (2016, p. 94):

As inovações se materializam pelo reconhecimento de formas alternativas de saberes e experiências, nas quais se imbricam objetividade e subjetividade, senso comum e ciência, teoria e prática, cultura e natureza, anulando dicotomias e procurando gerar novos conhecimentos.

Nesse sentido, inovação pedagógica implica o reconhecimento do outro e das diferenças, trabalhar na intenção de transformar e emancipar, promover as relações sociais entre os sujeitos. Essa perspectiva amplia o conceito de aula e de trabalho pedagógico para além dos modelos de formatação e propõe uma reconfiguração dos papéis dos diferentes atores, participantes do contexto educacional.

\section{Inclusão}

A discussão sobre inclusão constitui-se a partir da defesa da educação como um direito fundamental e indisponível dos indivíduos, necessária para uma sociedade mais justa. A Constituição Federal de 1988 apresenta determinações que norteiam a educação inclusiva no Brasil. O artigo 3. ${ }^{\circ}$, inciso IV, desta Lei trata sobre a aplicação do princípio inclusivo: "Promover o bem de todos sem preconceito de origem, raça, sexo, cor, idade e quaisquer outras formas de discriminação".

Incluir, nos espaços e tempos escolares, os diferentes sujeitos é um dos maiores desafios a ser alcançado em todas as etapas da educação escolar (AINSCOW, 2009; 
SANTOS, 2003; GLAT, PLETSCH E FONTES, 2007; SASSAKI 1997; MATOS E MENDES, 2014).

Apesar das discussões concernentes ao tema, tanto internacionais quanto nacionais, ainda falta clareza às ações que precisam ser realizadas para que as políticas e as práticas inclusivas avancem de fato.

Para Sassaki (1997), a inclusão pode ser compreendida como o processo contínuo pelo qual a escola se adapta para inserir, em seus espaços e processos de ensino e aprendizagem, pessoas que historicamente se encontram excluídas desse direito constitucional e, simultaneamente, preparando-se para assumir seus papéis na sociedade.

Essa ideia de conceber inclusão como um processo ininterrupto é defendida também por outros autores. Para Ainscow (2009), trata-se de um processo de transformação de valores em ação, resultando em práticas e serviços educacionais, em sistemas e estruturas que incorporam tais valores. Isso significa que a inclusão poderá ser totalmente compreendida somente quando seus valores fundamentais forem exaustivamente clarificados em contextos particulares.

Compreende, portanto, esforços de todos os autores educacionais a fim de identificar e eliminar barreiras no ambiente escolar. Trata-se de transformar a cultura institucional "numa cultura orientada pela e para a inclusão" (SANTOS, 2003, p. 64).

\section{ENCAMINHAMENTO METODOLÓGICO DA INVESTIGAÇÃO}

Na tentativa de compreender como os gestores da Ufop concebem interculturalidade, inovação pedagógica e inclusão, foi elaborado um questionário com questões abertas envolvendo esses três conceitos. Segundo Marconi e Lakatos (1999), o questionário tem como objetivo obter respostas acerca de um determinado tema ou situação. Nesse sentido, o questionário foi aplicado aos gestores da Ufop.

O estudo foi realizado em quatro etapas complementares: estudo teórico prévio sobre o tema; elaboração do instrumento de coleta de dados; coleta; e análise de dados. As duas primeiras foram construídas em cooperação com as universidades nacionais e internacionais participantes do Observatório Internacional de Inclusão, Interculturalidade e Inovação Pedagógica (OIIIIPe), por meio de reuniões presenciais e virtuais, ocorridas em 2016 e 2017. 
Para a construção do instrumento de coleta de dados levaram-se em conta critérios fundamentais para a elaboração de perguntas em pesquisas qualitativas, como: consideração dos objetivos da pesquisa; amplitude da questão para permitir o desvelamento de informações pertinentes ao tema da pesquisa; cuidado para evitar indução de respostas (SZYMANSKI, 2011). Elaborou-se, assim, o questionário com perguntas norteadoras, cujo objetivo era trazer à tona as concepções dos gestores da Ufop acerca dos conceitos de interculturalidade, inovação pedagógica e inclusão. O questionário foi enviado a 120 gestores da Ufop, no mês de maio de 2017. A relação dos sujeitos da pesquisa e seus endereços eletrônicos foram disponibilizados pelo setor de Registro Acadêmico da Pró-Reitoria de Graduação da Ufop. Além do questionário, o arquivo enviado continha uma Carta de Apresentação do estudo e o Termo de Consentimento Livre e Esclarecido. ${ }^{9}$

Delimitamos o prazo de 30 dias para envio das respostas, considerando o tempo previsto no cronograma. Entretanto, foi necessário reencaminhar o convite e estender o prazo de devolução para que obtivéssemos o total de 38 participantes.

\section{OS ACHADOS DA PESQUISA: COMO OS GESTORES DA UFOP PERCEBEM AS PROPOSIÇÕES INTERCUTURALIDADE, INOVAÇÃO PEDAGÓGICA E INCLUSÃO}

Dos 120 questionários enviados obtivemos 31,67\% de respostas. Assim, a amostra, em conformidade com os objetivos do estudo, foi composta por 38 gestores, sendo pró-reitores, coordenadores de cursos de graduação (bacharelados e licenciaturas), chefe de departamentos e diretores de unidades acadêmicas.

O Quadro 1 apresenta a amostra de gestores.

Quadro 1 - Caracterização por setor, cargo e número de respondentes da amostra de gestores investigados

\begin{tabular}{|c|c|c|c|}
\hline Setor & Cargo & Questionários enviados & Respostas \\
\hline Reitoria & Reitora; Prefeito & 2 & 0 \\
\hline Pró-reitoria & Pró-reitor(a) & 6 & 1 \\
\hline
\end{tabular}

\footnotetext{
${ }^{9}$ A pesquisa foi submetida e aprovada pelo Comitê de Ética em Pesquisa (CEP) do Centro de Filosofia e Ciências Humanas (CFCH) da Universidade Federal do Rio de Janeiro (UFRJ). Os gestores participantes, depois de receberem as informações referentes à pesquisa, consentiram em contribuir para o trabalho assinando o Termo de Consentimento Livre e Esclarecido.
} 


\begin{tabular}{|c|c|c|c|}
\hline Unidade Acadêmica & Diretores(as) & 12 & 9 \\
\hline $\begin{array}{c}\text { Colegiado de Curso - } \\
\text { Licenciaturas }\end{array}$ & Coordenadores(as) & 13 & 7 \\
\hline $\begin{array}{c}\text { Colegiado de Curso - } \\
\text { Bacharelados }\end{array}$ & Coordenadores(as) & 38 & 11 \\
\hline Departamentos & Chefe & 43 & 10 \\
\hline \multicolumn{2}{|c|}{ Total } & 120 & 38 \\
\hline
\end{tabular}

Fonte: Elaborado pelos autores.

Do total de respondentes apenas um setor não foi representado, a Reitoria. Aquele com menor representação foi o setor da Pró-reitoria, de seis, apenas um participou. O mais bem representado foi o setor Unidade Acadêmica, com $80 \%$ de participação.

\section{Discussões}

Depois de analisarmos as respostas coletadas por meio do questionário, elas foram separadas em três categorias, considerando os três conceitos abordados. Torna-se necessário esclarecer que o texto aqui apresentado é um recorte das respostas dos gestores que entendemos, em um primeiro momento, relevantes para se pensar os três conceitos e sua relação com a universidade. Explicitamos ainda que uma análise mais ampla será consolidada no relatório de pesquisa e posteriormente publicada. Para a discussão, iniciaremos com o conceito de inclusão e as representações identificadas nas respostas dos dirigentes.

Para o conceito de inclusão, as palavras que se repetem e que mais o traduzem são: acolhimento, acesso, oportunidade, minimizar a exclusão, pluralidade, inserção social, diferenças, direitos, quebrar paradigmas, políticas de participação para todos. É importante ressaltar que as representações dos dirigentes envolvem desde o acolhimento do sujeito na universidade até aspectos relacionados ao direito e ao respeito às diferenças.

O conceito de inclusão aparece fortemente ligado ao acesso dos sujeitos às instituições de ensino. Essa perspectiva nos chama a atenção, se considerarmos que a sociedade se organiza e se constitui, de alguma forma, movida pela educação. Nesse caso, as instituições de ensino e, principalmente, as instituições públicas de ensino cumprem um papel de acolhimento e formação dos sujeitos, garantindo-lhes uma educação de base cidadã. A construção de uma sociedade democrática passa, necessariamente, pelo reconhecimento das 
diferenças e pela sua centralidade nas lutas pelo reconhecimento dos direitos (SANTOS, 2003; MATOS; MENDES, 2014).

O reconhecimento da diferença e a construção de uma sociedade inclusiva vão além da perspectiva de acolhimento dos sujeitos em instituições escolares. É preciso considerar a inclusão em sua complexidade, levando em conta não somente os aspectos da diversidade social, mas outros de grande importância, como os aspectos políticos e éticos (MATOS; MENDES, 2014). Considerando o entendimento das autoras, é possível identificar que algumas falas avançam, um pouco, para além do acolhimento ou do acesso à educação de qualidade, apontando alguns aspectos que se encontram no campo do respeito às diferenças, por exemplo:

A ideia básica seria a de que o sistema educacional, em vários níveis, pudesse atender adequadamente diferentes tipos de pessoas, sem privilegiar um tipo determinado

$\mathrm{Ou}$ (Questionário respondido por gestor da Ufop, em junho de 2017).

Eu defino inclusão em educação como o conjunto de ações e reflexões feitas em prol do exercício de processos educativos que se pautem pelo princípio do reconhecimento, respeito e valorização de cada pessoa com as suas características singulares (Questionário respondido por gestor da Ufop, em junho de 2017).

E possível perceber que essas respostas indicam a perspectiva de valorização dos sujeitos independentemente de suas características específicas. Os aspectos culturais, políticos e éticos constituem-se em elementos basais para a formação de uma sociedade mais democrática e inclusiva. $\mathrm{O}$ processo de inclusão está intrinsecamente relacionado à remoção de barreiras que possam impedir ou dificultar qualquer sujeito de exercer seu direito de participação e aprendizagem no campo escolar (CARVALHO, 2000).

Mesmo que algumas falas apontem para perspectivas mais amplas no sentido da compreensão do que seja a educação inclusiva, é possível afirmar que o conceito de inclusão merece ser debatido no âmbito da Ufop como forma de se construir um entendimento mais homogêneo sobre o conceito e, assim, pensar políticas mais inclusivas. As respostas ainda estão distantes do que Glat, Pletsch e Fontes (2007, p. 344) compreendem:

Educação inclusiva significa pensar uma escola em que é possível o acesso e a permanência de todos os alunos, e onde os mecanismos de seleção e discriminação, até então utilizados, são substituídos por procedimentos de identificação e remoção das barreiras para a aprendizagem. 
Para Ainscow (2009), faz-se necessário compreender inclusão educacional como um processo de transformação de valores em ação.

O segundo conceito abordado foi o de interculturalidade. Optamos por manter a mesma perspectiva de tratamento das respostas. Resumimos aqui, com algumas palavras, as concepções que mais se repetem. Nas falas detectamos as palavras ou expressões: práticas culturais diferentes, espaços plurais, convivências culturais, diversidade, diversidade e diferentes culturas.

A partir dos termos apresentados supra, é possível identificar que eles de alguma forma explicitam a ideia de interculturalidade. Entretanto, ao mesmo tempo, verifica-se que esses termos são genéricos. Por mais que, de alguma maneira, nos remetam ao conceito de interculturalidade, eles não o explicam. Para Fleury (2009), a questão-chave da interculturalidade está no campo da complexidade. É necessário não somente respeitar as diferenças, como também integrá-las a fim de que sejam potencializadas e reforcem as conexões entre os diversos agentes e os contextos os quais lhes são próprios. O processo de inclusão efetiva-se e torna-se de fato inclusivo quando há imersão, vivência e diálogo nas diferentes culturas. Na mesma direção, Romero (2010) afirma a necessidade de convivência em posição de diálogo e negociação.

Considerando ainda o conjunto de palavras selecionadas dos questionários e que expressam o entendimento do que seja interculturalidade, é possível trazer à tona não somente a complexidade de definir tal termo, como também a dificuldade de conceituar diferença e igualdade. Em pesquisa desenvolvida com professores da educação básica, Candau (2012) revela que, nas narrativas dos professores, foi identificada a recorrência dos dois termos. Igualdade aparece na perspectiva da homogeneização, da uniformização. Essa visão dos professores, de certa forma, torna invisíveis as diferenças dentro dos espaços escolares e contribui para uma monocultura pedagógica. O conceito de diferença não emerge como diferença, e sim como algo a ser concertado, problema a ser resolvido. É interessante ressaltar que a diferença aparece como algo que foge ao padrão de normalidade e precisa ser a este reconduzido.

A dificuldade que observamos nas respostas dos gestores ao definirem de forma mais precisa o conceito de interculturalidade remete-nos às discussões de Candau (2012). Podemos aqui, de algum modo, entender que o reducionismo do conceito de interculturalidade a termos 
usuais pode implicar uma restrição de políticas e ações que, de fato, favorecem a emergência das diferenças nas instituições educacionais e na sociedade de forma geral.

A terceira discussão insere-se no campo da inovação pedagógica. Coletamos respostas dos gestores da Ufop e, da mesma maneira, selecionamos palavras que evidenciassem as representações que possuem do conceito. As palavras ou termos que mais ilustram as respostas são: práticas inclusivas e interculturais, metodologias e recursos inovadores, metodologias ativas, práticas e recursos, novas estratégias pedagógicas de ensino e de aprendizagem, novas práticas, novas metodologias de ensino.

Temos aqui algo não muito diferente do que aconteceu com o conceito de interculturalidade. Diferente da conceituação de inclusão, interculturalidade e inovação pedagógica são definidos mais genericamente. Esse é um dado importante para pensarmos em quanto esses conceitos ainda podem estar distantes do universo escolar e, particularmente, do universo do ensino superior. É algo preocupante quando nos damos conta de que, nessa etapa de formação, estamos desenvolvendo profissionais que atuarão no mercado de trabalho com um provável desconhecimento e distanciamento das discussões acerca do tema.

Se para Franco (2015) as práticas pedagógicas são aquelas que se movimentam para materializar certas expectativas pedagógicas, e essas práticas não são esvaziadas de intenção, muito pelo contrário, então não é possível definir inovação pedagógica de forma tão simplória. Inovação pedagógica está para além de mudanças nas estratégias de ensino e de aprendizagem. Ela diz de uma práxis, de um objeto que possui cientificidade e que necessita ser planejado com o objetivo de intervir e transformar realidades (FRANCO, 2015).

A conceituação dada pelos gestores da Ufop sobre inovação pedagógica reflete um limite na compreensão do conceito e leva-nos a refletir, novamente, sobre como esses conceitos circulam no âmbito do ensino superior e como podem ser absorvidos e incorporados pela instituição. A universidade e, principalmente, a universidade pública cumprem um papel fundamental na formação de profissionais não somente qualificados tecnicamente, mas capazes de olhar para a sociedade e enxergar as suas multiplicidades e diversidades. É preciso ir além de práticas regulatórias e caminhar para práticas mais emancipatórias, como nos diz Veiga (2003).

\section{CONSIDERAÇÕES FINAIS}


A partir da análise dos dados da pesquisa e do pensamento dos autores com os quais dialogamos, podemos elencar alguns desafios a serem superados para a efetivação de um trabalho pedagogicamente intercultural, inovador e que remete à inclusão na Ufop. São eles:

1. Considerar a educação intercultural como um princípio orientador na formulação das políticas, elaboração das propostas pedagógicas e efetivação das práticas escolares na sua globalidade.

2. Desenvolver processos de educação no interior de nossas universidades que não anulem as diferenças humanas.

3. Compreender a educação escolar como o processo construído pela relação tensa e intensa entre diferentes sujeitos.

4. Desconstruir o caráter homogeneizado predominante e reconstruir propostas pedagógicas interculturais, inovadoras e inclusivas, contextualizadas e com ênfase nas diferenças entre os sujeitos.

5. Criar contextos interativos e um ambiente criativo e propriamente formativo.

$\mathrm{O}$ enfretamento desses desafios se dará à medida que nos dispusermos a caminhar sob o ponto de vista do diálogo, do respeito às diferenças, do reconhecimento do outro como ele é, não como o idealizamos. Consideramos que o desafio principal está em vincular propostas de uma educação intercultural, inovadora e inclusiva nos debates e discussões no interior de nossas universidades.

\section{REFERÊNCIAS}

AINSCOW, Mel. Tornar a educação inclusiva: como essa tarefa deve ser conceituada? In: FÁVERO, Osmar et al. (Org.). Tornar a educação inclusiva. Brasília: Unesco, 2009. p. 1123.

BRASIL. Constituição (1988). Constituição da República Federativa do Brasil. Brasília: Senado Federal, Centro Gráfico, 1988.

Declaração Mundial sobre Educação para Todos: plano de ação para satisfazer as necessidades básicas de aprendizagem. Unesco, Jomtiem/Tailândia, 1990.

Parâmetros Curriculares Nacionais: pluralidade cultural e
orientação sexual. Brasília: MEC/SEF, 1997.
Estudos Censo da Educação Superior: 2011 - Resumo técnico. Brasília: Instituto Nacional de
e Pesquisas Educacionais Anísio Teixeira, 2013. Disponível em:


<http://download.inep.gov.br/educacao_superior/censo_superior/resumo_tecnico/resumo_tec nico_censo_educacao_superior_2011.pdf>.Acesso em: 10 jan. 2017.

CANDAU, Vera Maria. Sociedade, educação e cultura. Petrópolis: Vozes, 2002.

Direitos humanos, educação e interculturalidade: as tensões entre igualdade e diferença. In: (Org.). Educação intercultural na América Latina: entre concepções, tensões e propostas. Rio de janeiro: 7 Letras, 2009. p. 154-173.

Diferenças culturais, cotidiano escolar e práticas pedagógicas. Currículo sem Fronteiras, v. 11, n. 2, p. 240-255, 2011.

Diferenças culturais, interculturalidade e educação em direitos humanos. Educação $e$ Sociedade, Campinas, v. 33, n. 118, p. 235-250, jan.-mar. 2012. Disponível em: <http://www.cedes.unicamp.br>. Acesso em: 5 jan. 2017.

CARVALHO, R. E. Removendo barreiras para a aprendizagem. Porto Alegre: Mediação, 2000 .

CUNHA, Maria I. da. Inovações na educação superior: impactos na prática pedagógica e nos saberes da docência. Em Aberto, Brasília, v. 29, n. 97, p. 87-101, set.-dez. 2016.

DECLARAÇÃO DE SALAMANCA E LINHAS DE AÇÃO SOBRE NECESSIDADES EDUCATIVAS ESPECIAIS. Brasília, Corde, 1994. Disponível em: <http://www.mec.gov.br/seesp/pdf/declaracao.pdf>. Acesso em: 5 jan. 2017.

FLEURI, Reinaldo Matias (Org.). Intercultura: estudos emergentes. Ijuí: Unijuí, 2002. Intercultura e educação. Revista Brasileira de Educação, n. 23, p. 16-35, 2003.

- Complexidade e interculturalidade: desafios emergentes para a formação de educadores em processos inclusivos. In: FÁVERO, Osmar et al. (Org.). Tornar a educação inclusiva. Brasília: Unesco, 2009. p. 65-88.

FRANCO, Maria Amélia S. Práticas pedagógicas de ensinar e aprender: entre resistências e resignações. Educação e Pesquisa, São Paulo, v. 41, n. 3, p. 601-614, jul.-set. 2015.

GLAT, Rosana; PLETSCH, Márcia D.; FONTES, Rejane de S. Educação inclusiva \& educação especial: propostas que se complementam no contexto da escola aberta à diversidade. Educação Santa Maria, v. 32, n. 2, p. 343-356, 2007 Disponível em: <http://www.ufsm.br/ce/revista>. Acesso em: 26 jan. 2014.

MARCONI, Maria de Andrade; LAKATOS, Eva Maria. Técnicas de pesquisa. 3. Ed. São Paulo: Atlas, 1999.

MATOS, Selma Norberto; MENDES, Enicéia Gonçalves. A proposta de inclusão escolar no contexto nacional de implementação das políticas educacionais. Praxis Educacional, Vitória 
da Conquista, v. 10, n. 16, p. 35-59, 2014.

ROMERO, Carlos Giménez. Interculturalidade e mediação. Caderno de Apoio à Formação. Lisboa: Alto Comissariado para a Imigração e Diálogo Intercultural, 2010.

SANTOS, Mônica Pereira dos. O papel do Ensino Superior na proposta de uma educação inclusiva. Revista Movimento, Faculdade de Educação da UFF, n. 7, p. 78-91, maio 2003.

SASSAKI, Romeu K. Inclusão: construindo uma sociedade para todos. Rio de Janeiro: WVA, 1997. (Coleção Inclusão.)

SZYMANSKI, Heloisa; ALMEIDA, Laurinda Ramalho de; PRANDINI, Regina Célia Almeida Rego (Org.). A entrevista na pesquisa em educação: a prática reflexiva. 4. ed. Brasília: Líber Livro, 2011.

VEIGA, Ilma P. A. Inovações e projeto político-pedagógico: uma relação regulatória ou emancipatória? Caderno Cedes [online], v. 23, n. 61, p. 267-281, 2003. Disponível em: <http://dx.doi.org/10.1590/S0101-32622003006100002>. Acesso em: 6 jan. 2017.

WANDERLEY, Mariangela Belfiore. Refletindo sobre a noção de exclusão. In: SAWAIA, Bader. As artimanhas da exclusão: análise psicossocial e ética da desigualdade social. 2. ed. Petrópolis: Vozes, 2001. p. 16-26.

Recebido em: 07/10/2017

Aceito em: 25/01/2018 